\title{
Simultaneous Electrochemical Determination of Nicotinamide Adenine Dinucleotide and Ascorbic Acid at Carbon Nanotube Electrode
}

\author{
Yuki InOue,* Yuta OKaZaKI, ${ }^{*}$ Hitoshi Muguruma, ${ }^{* \dagger}$ Hitoshi InOue,** and Tatsuya OhSAwa** \\ *Shibaura Institute of Technology, 3-7-5 Toyosu, Koto, Tokyo 135-8548, Japan \\ **Nippon Shizai Co. Ltd., 1-5-6 Bakurou-machi, Chuo, Osaka 541-0059, Japan
}

\begin{abstract}
Simultaneous electrochemical determination of nicotinamide adenine dinucleotide (NADH) and ascorbic acid (AA) at a carbon nanotube electrode is presented. The discrimination of NADH and AA is conducted with the difference of peak potential by differential pulse voltammetry. Two well-distinguished anodic peaks, +0.56 and $+0.26 \mathrm{~V}$, due to NADH and AA are observed. The characteristics of those peaks were independent from each other. The attained characteristics for simultaneous determination of NADH and AA are (i) NADH measurement at the concentration range of $0.030-2.0 \mathrm{mM}$ in the presence of $1.2 \mathrm{mM} \mathrm{AA}$, and (ii) AA measurement at the concentration range of $0.030-2.0 \mathrm{mM}$ in the presence of $2.0 \mathrm{mM}$ NADH.
\end{abstract}

Keywords Carbon nanotube, simultaneous determination, nicotinamide adenine dinucleotide, ascorbic acid, differential pulse voltammetry

(Received March 9, 2016; Accepted March 18, 2016; Published July 10, 2016)

\section{Introduction}

Ascorbic acid (AA), known as vitamin $\mathrm{C}$, is a water-soluble chemical. AA is present in the human body such as in the brain, liver, leukocytes, and anterior pituitary lobes, and it plays an important role in metabolism, immunity, and digestion. AA is also used as a nutrient and antioxidant in foods, drugs, and cosmetics. Nicotinamide adenine dinucleotide (NADH) plays a pivotal role in energy production in the organelle of living cells. NADH is also a cofactor system for a large number of dehydrogenase enzymes and a component of biomarker systems. Therefore, determination of NADH and AA is very meaningful in medical, pharmaceutical, and food fields. Electrochemical detection of NADH and AA is a convenient methodology compared to other analytical methods. ${ }^{1-14}$ NADH and AA often coexist in biological samples, and the signals originating from those substances interfere with each other. However, the simultaneous determination of NADH and AA has not been done except in the preliminary work by Karimi-Maleh et al. ${ }^{1}$ However, they reported the simultaneous determination under low concentrations $(<0.2 \mathrm{mM})$, which caused only small interference between NADH and AA. Most research has addressed selective detection in which only one target was quantitatively detected and the other objects were eliminated. In a word, either $\mathrm{NADH}^{2-15}$ or $\mathrm{AA}^{16,17}$ was measured in a coexistence sample. In order to conduct the simultaneous determination, both NADH- and AA-selective electrodes would be required.

A carbon nanotube (CNT), which is the result of folding graphene layers into carbon cylinders, is one of the common

† To whom correspondence should be addressed.

E-mail: muguruma@shibaura-it.ac.jp materials used for this purpose because NADH and AA are easily oxidized..$^{2-8}$ This is probably because CNTs display excellent electrical conductivity, excellent catalytic activity, high mechanical strength, and high chemical stability. We demonstrate the simultaneous determination of NADH and AA at a concentration range of $0.03-2 \mathrm{mM}$ with the CNT electrode.

\section{Experimental}

Reagents

Multi-walled CNTs (4-12 layers, average length $200 \mu \mathrm{m}$ ) were produced by Taiyo Nippon Sanso Corporation (Tokyo, Japan). Acetonitrile, potassium dihydrogenphosphate, disodium hydrogenphosphate, and ascorbic acid were purchased from Kanto Chemical Co., Inc. (Tokyo, Japan). NADH was purchased from Wako Pure Chemical Industries, Ltd. (Osaka, Japan).

\section{Electrode preparation}

The electrode was formed on a sputtered Au substrate. The dimension of the opening for the working electrode was $9 \mathrm{~mm}^{2}$. The plasma generator produced by ULVAC Inc. VEP-1000 (Tokyo, Japan) was used to deposit a 2-nm-thick acetonitrile plasma-polymerized film (PPF) layer onto Au. The CNT was dispersed $(0.1 \% \mathrm{w} / \mathrm{v})$ in water solution containing nonionic surfactant $(0.5 \% \mathrm{w} / \mathrm{v})$. The CNT solution was dropped onto the PPF surface and dried. Subsequently, the CNT-adsorbed surface was treated with acetonitrile plasma using the following parameters: power, $200 \mathrm{~W}$; flow rate, $15 \mathrm{~mL} \mathrm{~min}^{-1}$; pressure, $0.6 \mathrm{~Pa}$; exposure time, $210 \mathrm{~s}$ (thickness: $6 \mathrm{~nm}$ ). These details are described in previous literature. ${ }^{18,19}$

\section{Measurement}

Electrochemical measurements were performed with an 

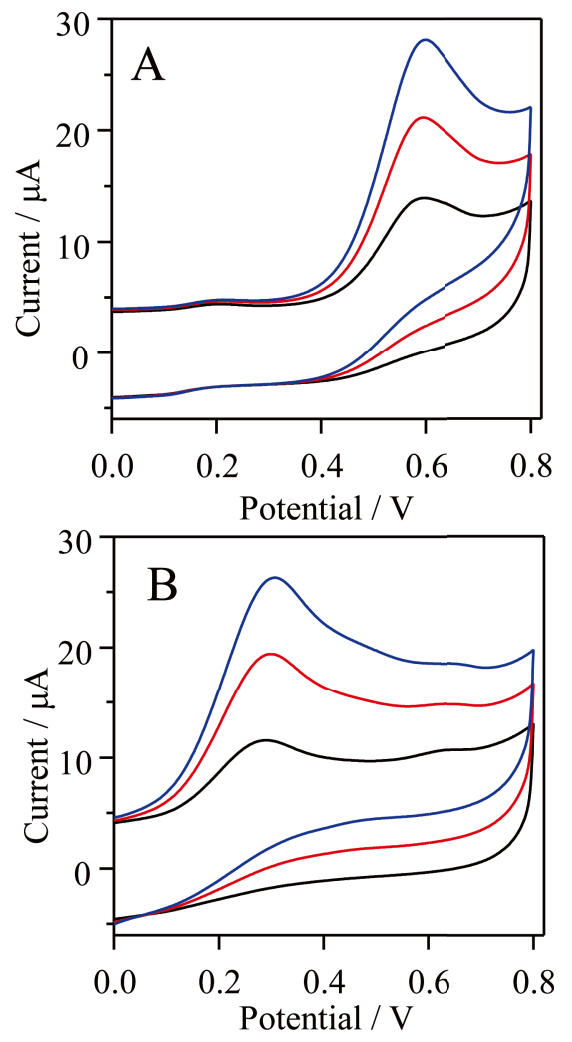

Fig. $1 \mathrm{CV}$ profiles of (A) NADH and (B) AA of the CNT electrodes. Analyte concentrations of $C V$ were $0.59,1.2$, and $1.7 \mathrm{mM}$. The sweep rate was $50 \mathrm{mV} \mathrm{s}^{-1}$. The electrolyte used was a $\mathrm{pH} 7.4,20 \mathrm{mM}$ phosphate buffer solution.

electrochemical analyzer (ALS Instruments, 644e). A threeelectrode configuration was used. Electrochemical measurements were carried out in a $5-\mathrm{mL}$ vessel at ambient temperature $\left(20^{\circ} \mathrm{C}\right)$. Differential pulse voltammetry (DPV) was carried out under the following parameters: amplitude, $50 \mathrm{mV}$; a voltage increment, $10 \mathrm{mV}$; pulse width, $0.05 \mathrm{~s}$; sample width, $0.02 \mathrm{~s}$; pulse period, $0.2 \mathrm{~s}$; and scan rate, $50 \mathrm{mV} \mathrm{s}^{-1}$.

\section{Results and Discussion}

Cyclic voltammetry (CV) is a useful tool for the fundamental evaluation of CNT electrodes. CV was performed to investigate the electrochemical response of the CNT electrode toward $\mathrm{NADH}$ and AA oxidation. Figure 1 shows $\mathrm{CV}$ profiles for the CNT electrodes. As can be seen, the increase in current due to the oxidation of NADH and AA was observed around +0.59 and $+0.30 \mathrm{~V}$, respectively. No reduction peaks due to NADH and AA were observed, showing that those are irreversible processes. Amperometric measurement will not allow for discrimination between $\mathrm{NADH}$ and $\mathrm{AA}$ because of the relatively higher oxidation potential of NADH than AA. At the potential for NADH oxidation, AA also will be oxidized. DPV determinations are designed to overcome this drawback because the discrimination is conducted with the difference of oxidized potential (peak separation). Furthermore, the DPV signal has much higher current sensitivity and better resolution than $\mathrm{CV}$ because of eliminating the non-Faradic current.

Figure 2 shows DPV for the simultaneous determination of $\mathrm{NADH}$ and AA at the CNT electrode. We varied the concentration of one of the analytes while keeping the
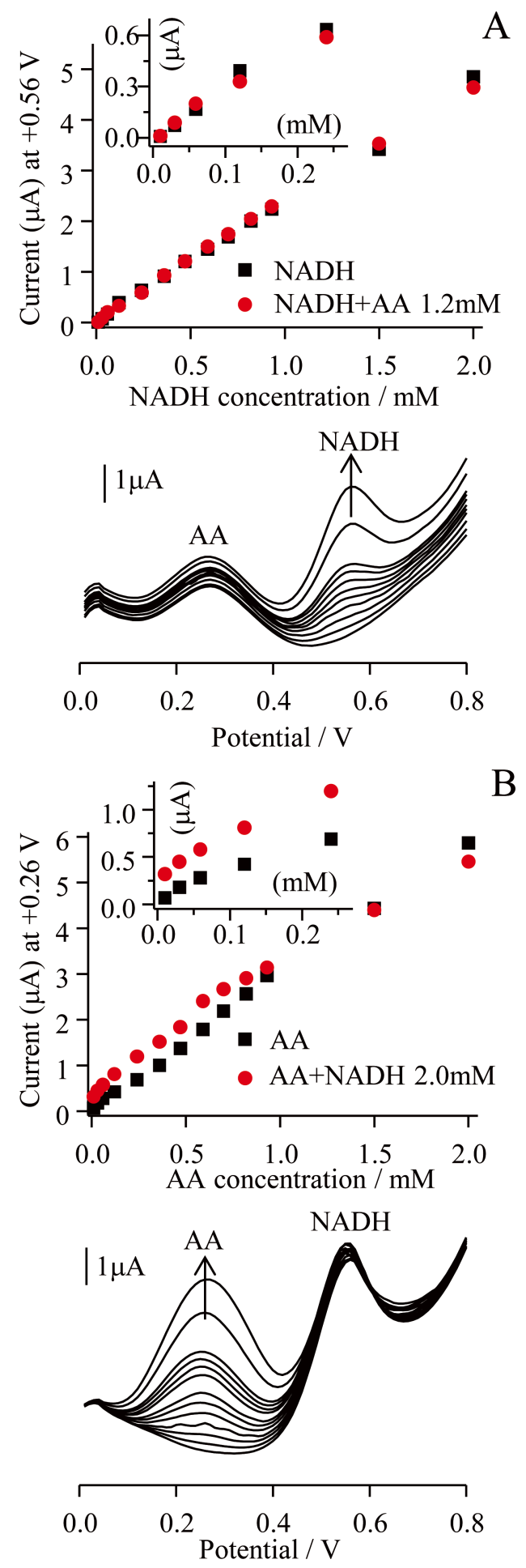

Fig. 2 DPV for the CNT electrode at different concentrations of (A) $\mathrm{NADH}$ in the presence of $1.2 \mathrm{mM}$ AA and (B) AA in the presence of $2.0 \mathrm{mM}$ NADH. Altering analyte concentrations were $0,0.12,0.24$, $0.36,0.47,0.59,0.70,0.82,0.93,1.5$, and $2.0 \mathrm{mM}$. The electrolyte used was a $\mathrm{pH}$ 7.4, $20 \mathrm{mM}$ phosphate buffer solution.

concentration of the other constant. The DPV exhibited the simultaneous determination of NADH and AA with the two well-distinguished anodic peaks of +0.56 and $+0.26 \mathrm{~V}$, corresponding to the oxidation of NADH and AA, respectively. The peak current and peak potential of the other one remained unaltered. The sensitivity of the CNT electrode toward the oxidation of NADH in the absence and presence $(1.2 \mathrm{mM})$ of 
AA was found to be 2.35 and $2.31 \mu \mathrm{A} \mathrm{mM}^{-1}$, respectively (Fig. 2A). The sensitivity of the CNT electrode toward the oxidation of AA in the absence and presence $(2.0 \mathrm{mM})$ of $\mathrm{NADH}$ was found to be 2.93 and $2.98 \mu \mathrm{A} \mathrm{mM}^{-1}$, respectively (Fig. 2B). The linear function of NADH determination was $I_{\mathrm{pNADH}}(\mu \mathrm{A})=0.0553+2.35 C_{\mathrm{NADH}}(\mathrm{mM})$ with linear range of $0.030-2.0 \mathrm{mM} \quad(r=0.999)$. The linear function of $\mathrm{AA}$ determination was $I_{\mathrm{pAA}}(\mu \mathrm{A})=0.0714+2.93 C_{\mathrm{AA}}(\mathrm{mM})$ with linear range of $0.030-2.0 \mathrm{mM}(r=0.999)$. This indicated that the oxidation processes of NADH and AA at the CNT electrode are independent from each other. Each sensing characteristic is similar with the single determination of $\mathrm{NADH}^{5,8,14}$ and AA. ${ }^{16,17}$ Therefore, simultaneous measurements of the two analytes are possible without any interference. The results can probably be ascribed to the characteristics of CNTs, including their nanostructure, catalytic activity, and electron transfer ability. ${ }^{20}$ Furthermore, there is a practical advantage in our research. The electrode previously reported by Karimi-Maleh et al. ${ }^{1}$ was composed of CNT, ruthenium(II) complex, and zinc oxide, whereas our electrode was based on CNT alone. Utilization of the electron transfer mediator does not only involve a complicated procedure for fabrication, but also causes problems such as poor reproducibility, lack of long term-stability, and toxicity. We achieved reproducibility, durability, proper safety, and simple production.

\section{Conclusions}

We demonstrated simultaneous electrochemical determination of NADH and AA at the CNT electrode. Two well-distinguished anodic peaks +0.56 and $+0.26 \mathrm{~V}$ due to NADH and AA were observed by DPV measurement and those peaks were independent from each other. The method presented here will be a significant contribution toward the development of electrochemical determination toward these important chemicals.

\section{References}

1. H. Karimi-Maleh, F. Tahernejad-Javazmi, M. Daryanavard,
H. Hadadzadeh, A. A. Ensafi, and M. Abbasghorbani, Electroanalysis, 2014, 26, 962.

2. J. Filip, J. Ŝefčovičová, P. Tomčík, P. Gemeiner, and J. Tkac, Talanta, 2011, 84, 355.

3. H. Teymourian, A. Salimi, and R. Hallaj, Talanta, 2012, 90 , 91.

4. F. S. Saleh, T. Okajima, F. Kitamura, L. Mao, and T. Ohsaka, Electrochim. Acta, 2011, 56, 4916.

5. H. Teymourian, A. Salimi, and R. Hallaj, Biosens. Bioelectron., 2012, 33, 60.

6. K.-C. Lin, Y.-S. Li, and S.-M. Chen, Sens. Actuators, B, 2013, 184, 212.

7. L. Fotouhi, F. Raei, M. M. Heravi, and D. Nematollahi, $J$. Electroanal. Chem., 2010, 639, 15.

8. B. Ge, Y. Tan, Q. Xie, M. Ma, and S. Yao, Sens. Actuators, $B, 2009,137,547$.

9. D. Sangamithirai, V. Narayanan, B. Muthuraaman, and A. Stephen, Mater. Sci. Eng. C, 2015, 55, 579.

10. D. Zhang, R. Zhang, C. Xu, Y. Fan, and B. Yuan, Sens. Actuators, B, 2015, 206, 1.

11. M. Maduraiveeran, M. Amiri, and A. Chen, Biosens. Bioelectron., 2015, 66, 474.

12. A. Gasnier, M. L. Pedano, M. D. Rubianes, and G. A. Rivas, Sens. Actuators, B, 2013, 176, 921.

13. L. Rotariu, O.-M. Istrate, and C. Bala, Sens. Actuators, B, 2014, 191, 491.

14. O.-M. Istrate, L. Rotariu, V. E. Marinescu, and C. Bala, Sens. Actuators, B, 2016, 223, 697.

15. V. S. Vasantha and S.-M. Chen, Electrochim. Acta, 2006, 52,665 .

16. B. Liu, L. Luo, Y. Ding, X. Si, Y. Wei, X. Ouyang, and D. Xu, Electrochim. Acta, 2014, 142, 336.

17. S. Kim, T. L. Kim, A. Yu, J. Lee, S. C. Lee, C. Lee, M. H. Kim, and Y. Lee, Sens. Actuators, B, 2014, 196, 480.

18. H. Muguruma, T. Hoshino, and Y. Matsui, ACS Appl. Mater. Interfaces, 2011, 3, 2445.

19. H. Muguruma, R. Nagata, R. Nakamura, K. Sato, S. Uchiyama, and I. Karube, Anal. Sci., 2000, 16, 347.

20. K. Gong, Y. Yan, M. Zhang, L. Su, S. Xiong, and L. Mao, Anal. Sci., 2005, 21, 1383. 